\title{
The Contemporary Filipino Family Life: Towards A Comprehensive Family-Oriented Counseling Program
}

\author{
Argel B. Masanda \\ Central Luzon State University Science City of Muñoz, Nueva Ecija, Philippines.
}

How to cite this paper: Argel B. Masanda. (2021) The Contemporary Filipino Family Life: Towards A Comprehensive Family-Oriented Counseling Program. Journal of Humanities, Arts and Social Science, 5(1), 16-22.

DOI: 10.26855/jhass.2021.01.003

Received: December 21, 2020

Accepted: January 15, 2021

Published: January 25, 2021

*Corresponding author: Argel B. Masanda, Central Luzon State University Science City of Muñoz, Nueva Ecija, Philippines.

Email: argelmasanda@clsu.edu.ph

\begin{abstract}
This study is an exploration of the contemporary Filipino family interrelationships and dynamics with the objective of proposing a family-oriented counseling program which can be implemented for a better family wellbeing. Nine families from the province of Nueva Ecija were selected and interviewed to assess their overall family functioning. Data gathered were analyzed thematically. The qualitative data's trustworthiness where squared through triangulation, stability check, and member checking. Yielded themes were then used as a benchmark for the organization of a comprehensive family counseling program. Major themes revolved around family relationships, familial decision making, and societal judgmental attitudes. Hence, it can be assumed that the contemporary Filipino family can be best understood from the viewpoints of these themes. The proposed family-oriented counseling program was designed based on the overall implications of the said themes. This consisted of responsive and expansive counseling strategies that can be piloted and validated as a part of an overall community-based mental health program. Further, drawing from these results, it was conclusive that the Filipino families are constantly changing so as to stay relevant in the changing world. This change may unsurprisingly result to challenges which can be dealt with using a guidance-oriented approach. Pertinent conclusion about the implications of the gathered data was further drawn and relevant recommendation were hereby proposed which are viably open for further explorations.
\end{abstract}

\section{Keywords}

Contemporary, Filipino, Family, Counseling, Program

\section{Introduction}

Filipino families by culture are known to be closely knitted and centered on good and deep relationships among its members. The Filipino family is the center of the Philippine social structure and includes the nuclear family, aunts, uncles, grandparents, cousins and honorary relations such as godparents, sponsors, and close family friends (Villareal, 2018). Even though series of colonization and ongoing distraction to Filipino culture and traditions are perennial-as evident to the colonial mentality observed in various sectors and medias specifically, Filipino families remain strong and solid in general. This does not safeguard them from certain familial problems that are both external and internal in nature. Societal and familial distresses may inevitably develop both from within (intrafamilial) and without (extrafamilial) the family system (Masanda, 2019) which may negatively impact its dynamics and equilibrium.

To further situate the contemporary Filipino families, Cruz (2014) argued that Filipino families are in transition; 
the society changes, the technology advances and so as the family. To add to this, transnational families are becoming more prevalent where family members are living in different countries especially the parents (Philippine Center for Population and Development, 2014). As one of the results, families in which grandparents raise children are gaining more and more traction, this is technically called "skip generation families" (PCPD). Similarly, technology can also impact family development negatively; in 2017, it was reported by the Philippine Daily Inquirer that Filipinos spent an average of 4 hours and 17 minutes per day on social media such as Facebook, Snapchatand Twitter. Further, 40 percent of kids under 2 years old have used a smartphone or tablet and 2 percent of 8 years and above have used smartphone or tablet (PDI, 2017). In effect, even though contemporary technology bridges the gap between transnational families in terms of communication, excessive time spent in social media may harshly affect the quality of relationships among families (Villareal, 2018).

Changing trends in the family system in the contemporary times are well deserving to be noted in order to properly provide guidance to all family members. For instance, the emergence of solo parent families is now becoming a drift; according to the national survey of PCPD on 2013, approximately 14\%-15\% of the population are solo parents and 7.5\% of the Filipino youths aged 15-24 were raised by solo parents, i.e., father only or mother only. In a related fashion, the National Demographic and Health Survey, the percentage of women aged 149 who are in a 1 ive-in arrangement increased from 6\% in 1998 to14.5\% in 2013. In a similar note, the percentage of youth aged 15-24 in a live-in arrangement increased from 4.7\% in 1994 to 13.8\% in 2013 (Young Adult Fertility and Sexuality Survey, 2014).

Generally, therefore, the composition of Filipino families can be said as changing as the emergence of the 'not-so-usual' families (e.g., Villareal, 2018) is evident. There are other factors that might contribute to this changing view of the composition of the Filipino families which may impact their equilibrium and dynamics as a system. Hence, a responsive approach to this familial situation must be faced and addressed. The guidance and counseling profession has absolutely a great role to play in such scenario as guidance services go beyond the boundaries of the school. As a response henceforth to this clamor, this paper aimed to build a bridge in dealing with familial concerns using a guidance-oriented approach through a counseling program.

\section{Methods}

\subsection{Research Design}

This study utilized a qualitative approach using the case study design where the phenomenological experiences of each family member were given importance that served as an objective baseline of the designed and proposed family-oriented guidance program.

\subsection{Participants}

Nine (9) families from Science City of Muñoz, San Jose City and Lupao, Nueva Ecija, respectively served as the respondents of this study. Each of the following was selected through the following criteria: (a) those with predominantly existing family-related concerns or problems; (b) those with unconventional family structures; and (c) those who are willing to share and open up their stories. The families' household composition ranged from 2-8 members with $65 \%$ of whom have married status and $35 \%$ were unmarried. Mothers' educational level was as followed: $11 \%$ were primary level educated, $78 \%$ were secondary level educated, and $11 \%$ were tertiary level educated. Fathers' educational level, on the other hand was as followed: $13 \%$ were primary level educated, $62 \%$ were secondary level educated, and $25 \%$ were tertiary level educated. $78 \%$ of the mothers were housewives and $22 \%$ were domestic helpers. Father's occupation consisted of the following: $25 \%$ were farmers, $25 \%$ were tricycle drivers, $25 \%$ were government employees, $12.5 \%$ were overseas workers, and $12.5 \%$ were construction workers. $75 \%$ of the families are still sending their children to the school while $12.5 \%$ of whom have already finished all their educations and $12.5 \%$ were still expecting. Each of the presently available family members was interviewed comprehensively.

\subsection{Instrumentation}

With the nature of the study, it made use of unstructured interview guide in investigating the dynamics of each of the family which can be used in the design of a guidance program. The main study question was "Kumusta po ang ugnayan ninyong magpa-pamilya? (how is your relationship with your family members?)”. Other major questions were based on the subsequent answers following therein.

\subsection{Data Gathering Procedures}


Each of the researcher pinpointed prospective families as described above and were visited to discuss with them the objectives of the study and to solicit their consent and willingness to participate. Interviews were followed; each member was interviewed individually followed by a focus group discussion among the entire family. Termination of the data gathering was facilitated by providing tokens of appreciation with each of the family.

\subsection{Data Analysis}

Data were analyzed thematically by tracking the patterns of emerging themes across the rich interview databank from each family member and all the nine families. Each extracted theme was grouped together to form cluster themes. Interpretative Phenomenological Analysis (IPA) guided the analysis of data and the extraction, forming, and clustering of the themes.

\subsection{Trustworthiness Check}

To check the qualitative data's trustworthiness, the study employed the following: (a) triangulation: the researchers grouped together to individually check whether the already extracted themes fit together as initially analyzed; (b) member checking: the researchers went back to selected families to check with them whether the extracted themes as interpreted from what they said during the interviews actually balanced out to what they actually meant; and lastly, (c) stability check: the $9^{\text {th }}$ family's interview data were set aside at first and were checked if it fits to the already extracted, formed, and clustered themes. All trustworthiness measures balanced out.

\section{Results and Discussion}

As explored through qualitative investigations, the researchers able to extract rich data about the family dynamics of the nine families who participated in this study. These data were clustered in three major themes with each having its own subthemes as illustrated below (Table 1):

Table 1. The summary of themes

\begin{tabular}{cc}
\hline Superordinate Themes & Subordinate Themes \\
\hline Family relationships & Trust within the family \\
& Forgiveness \\
Familial decision-making & Opening of doors for new people \\
& Communication as the key \\
Societal judgmental attitudes & Guided decision-making \\
& Stereotypes, prejudices, and discrimination \\
\end{tabular}

\subsection{Family relationships}

This is the most resounding among the themes generated in this study. Majority of the family members recognized that family love is not only revolving with one person but rather it takes all of them to build a strong and healthy family relationship. More specifically, the following subthemes provide detailed perspectives of the family members about what constitute a healthy and functional family relationship:

Trust within the family. One of the most important things needed in a healthy relationship is to make sure that there's enough trust among its' members that would enable a give and take relationship; one of the mothers heading a matriarchal family emphasized "kailangan marunong kang magbigay, hindi iyong ikaw lang at gusto mo lang ang masusunod... pagkatiwalaan mo mga kasama mo sa bahay kasi dapat lahat may boses, kahit sabihin mo pang ikaw ang kwan (lider ng tahanan [You should know how to give and be considerate of your family member's desires... you need to trust your housemates, everybody should have their voice even though you are (the leader of the house)]". Simply put, leadership in a household seem to center around the level of trust each and every one was entrusted with; love then, can be shown through trusting one another.

Forgiveness. Albeit love and trust are present within the family, it seemed inevitable that each family experiences trials that test their faith to one another. Common challenges that beset the participants' family system are financial problem, unemployment, disability, varying attitudes among each family member, adultery and/or concubinage 
which is partly due to long distance relationships between the couples which consequently lead to family brokenness both as a unit and as a system. In spite of this however, forgiveness was a chosen response by the housewives at the end of the day to achieve peace of mind, one of the housewives mentioned "kapag nagtanim tayo $\mathrm{ng}$ galit sa isang tao, hindi tayo magkakaroon ng peace of mind nung tumagal tagal na dapat alisin na yung mga galit na yun para magkaroon tayo ng kapayapaan [when you hold a grudge against someone, we cannot have a peace of mind, when time comes, we need to learn to forgive so we can have peace]". To them, forgiving is a sign of peace and not just to fix their family. It also enabled them to heal their hearts and to achieve peace of mind. In addition, forgiving is a step to accept again the person no matter what happen because of the strong love they have not just for the husband but most importantly, to their family. They recognized that this experience of their family is part of their imperfections that they have learned to live with about.

Opening of doors for new people. As can be understood from the cultural viewpoint of Filipino families, extending its arms to other people beyond the family's bloodline is a common practice of preserving its relationships. As one of the family members expressed "having friends is good and nice but having trusted friends is much nicer... they are already part of your family". Note that "trust" is a component of making a family extension, as previously stressed. On the flip side, one of the heads of the family cautioned and reckoned:

"huwag masyadong matiwala lalo na kung kailan mo lang nakilala. Sa pag-aakala mo na okay at sobra mo na silang mapagkakatiwalaan, magsasabi ka na ng mga hinaing mo na kung tutuusin ay hindi pala dapat. Magtira ka ng sikreto para sa sarili mo, hindi iyong alam ng lahat ang patungkol sa iyo."

"[Do not just trust anybody so easily especially if you've just met. You could think that they are trustworthy by sharing them your problems which you shouldn't in actuality. Reserve some secret about yourself instead of being an open book to everybody]"

Hence, a more balanced pathway of giving familial trust was emphasized or at least suggested to be learned by Filipino families in order to have a more meaning extended family relationships. This experience however, did not hinder the respondents to make more extensions in their family relationships.

\subsection{Familial decision-making.}

Embedded in a successful (or unsuccessful) transaction between and among family members is the value of good (or bad) decision making. Below are the specific factors that affect family's 6 decision-making process in relation to their overall family dynamics as a system:

Communication as the key. Unanimous of the families recognized that communication within their system and among them as parts of it is extremely important because it enables them to express their needs, wants, and concerns to each other. This is usually characterized by the degree of closeness among them, quality of bonding activities between them, specific abilities (or inabilities) among each member, and their proximity to one another. As a head of one of the families, one father explained "communication is needed when it comes to rendering a family. Open communication helps make an effective decision-making regarding family problem matters". Drawing from the data gathered, recognizing the importance of communication is the first step in developing a positive family culture, the second is perpetually practicing strategies to improve it. Similarly, maintaining healthy family communication is now seemingly becoming more important than ever because of our busy and dynamic lifestyles. A lack of it can seem to weaken the overall relationship among family members. Hence, taking time to talk over each members' current feelings is a big step toward forming a healthier family dynamic.

Guided decision making. Drawing from the value of communication above, this subtheme entails that consideration of the other family members' welfare is an ingredient for a better family dynamic "kailangang intindihin mo rin siya, halimbawa man na ganito ang gusto niya siyempre minsan pagbigyan mo na. hindi iyong laging ikaw ang binibigyan, dapat matuto ka ring magbigay. Give and take ika nga [you need to understand them, if they need something some time, give it to them... do not just prioritize your own, learn to give and take]". Family life, as the participants emphasized strongly, is a product of 'give and take' process where one member put things in and the other take things out. This kind of relationship characterized through making a balanced decision seem to be a concrete and effective recipe for long-term satisfaction between and among family members.On the other side, this give-and-take-relationship is crucially affected by family-oriented and related decisions are not easy to make especially when one family is just starting up. One of the participating head of the family recalled "ilang taon pa lamang ako noon at wala pa sa tamang edad. Mag-ieighteen pa lang ako nang binalak naming magpakasal. Mayroon ng pinagkasunduang petsa kung kailan kami ikakasal kaso sa kasamaang-palad, umurong siya [I was just very young 
back then, only turning eighteen when I decided to get married. There was already a decided date for our wedding unfortunately she retracted]". Therefore, careful considerations must be weighed first because impulsivity could be detrimental to the overall family dynamics. It could also be said furthermore that readiness to contribute to a better family building and guided decision making are crucial components of a give-and-take-relationship within Filipino families.

\subsection{Societal judgmental attitudes}

Being identified as the basic unit of society, Filipino families are not exempted from the damaging effects of societal judgments and the like. Since the families who participated in this study experienced certain intra and extra-familial societal stresses, they inescapably suffered from, but not limited to, the following:

Stereotypes, prejudices, and discriminations. With their unique family experiences compare to other families in their communities, majority of the participants reported experiencing disturbing means from their surroundings that caused them distress, worry or anxiety, upsetting, an unpleasant mental state by such effects as irritation, unfairness and distraction. These are brought by certain tags (biased collected belief against) about the family members, negative affective appraisal about the persons (prejudicial attitude) which led to discriminative behavior towards them, whether they think it could be or it actually materializes. One of them recollected:

“Ayaw n'ya ng lumabas ng bahay, diba dati nakikita mo s'ya (pointing to one of the daughters) na bumibili? Pero ngayon hindi na, ayaw n'ya na kasi may mga taong hindi ko alam kung may utak ba na alam na nga nila na ganun na nga sasabihin o imumustra pa nila na hindi na daw s'ya magbubuntis kasi may edad na s'ya".

"[She doesn't want to go out of house now, you saw her (pointing to one of the daughters) buying before, isn't it? But now she doesn't want to anymore because of those people whom I am unsure if they got brains at all because they are insensitive to her condition that she wouldn't get pregnant anymore because of her old age]".

Esteem-related issues.This unfair treatment caused them to feel indifferent and frustrated. In some instances, where communication is lacking among family members, some of them questions their worth and value as a person due to the problems they are experiencing and the reactions of, and non-support by, the society they are living in “minsan... madalas nga actually, ayaw ko na sa paligid ko, sa nangyayari sa amin, sa mga tao sa paligid ko kasi lagi nila kami pinagtsi-tsismisan...hindi ko na nga din alam kung gusto ko basa sarili ko, sa pamilya ko [sometimes... actually oftentimes, I do not like my surroundings, to what is happening to us, to the people around us because they always gossip about is... in fact, I am no longer sure if I still like myself, my family]". While the parents recognized that the problems, they are having were basically the results of their actions (or inactions) because they can do very little about it because they themselves need the help they should be providing for their children. In spite of this however, they find a way to deal with it day by day by taking things one step at a time, surrendering all to the Almighty, and clinging on the family love that they share together, no matter how difficult it tends to be at times.

\subsection{Proposed Counseling Program}

Guided by these results, this study proposes the following target competencies to be improved by a responsive and innovative counseling program to assist Filipino families in the contemporary times. These are outlined and chiefly described below (Table 2).

\section{Implications}

The contemporary Filipino family, as understood based on the premises of the results of the study and in conjunction with the literatures, is still changing. Nevertheless, Filipino families still continue to display great solidarity, loyalty and support of the blood group. Family is frequently seen as the Filipinos' primary social organization and often extended to bilateral family members which include consanguinity relatives of both the mother and father. Within the Philippine context, the family cohesiveness permeates all facets of the functioning society. Hence, the Filipino family is the major source of their stresses, sadness, pains, heartaches but also of emotional support, comfort, warmth, nurturing, protection and as well as security, paradoxically speaking.

Further, the constant changing of the Filipino families can be attributed to the fluctuating economic, cultural, social, educational, spiritual and other multifaceted factors that continue to affect the quality of relationships among Filipino 
families. This change however must be seen from a survival perspective as the process of modernization is continually catching up with the Filipino family. In essence, change must occur so that the families will endure to be relevant in a changing world. Changes inevitably results to challenges this context therefore, a guidance-oriented approach though a responsive counseling program can be designed to deal with the diminishing aspects of the Filipino families' dynamics. The designed program thus can be best seen as an ideal approach to better the overall family dynamics of the Filipinos and can be considered a part of a general mental health program that aims to build a stronger society by making families more cohesive and functional.

Table 2. Overview of the proposed counseling program

Extracted Themes

Trust within the family

Forgiveness

Opening of doors for new people

Communication as a key

Guided decision making

Stereotypes, prejudices, and discrimination

Esteem-related issues
Target Competencies and Counseling Techniques

Individual and/or group counseling and seminar approach to help parents reduce parental stress by enhancing their skills and knowledge in areas such as healthy child development, stress management, and effective parenting and discipline that will inculcate familial trusts among all members.

Group Counseling sessions in areas such as stress management, co-dependency, inner-child wellness, anger management, depression, and adolescent and parenting support groups. They usually meet on a weekly basis for a specified number of weeks.

Family education counseling to assist parents in learning important facts about their child's development and to practice new and effective parenting skills which helps the adult members of the families, especially the parents, to be the kind of nurturing and involved adults and/or parents they can be especially in the booming presence of extended family setting.

Filial therapy by utilizing play therapy techniques; parents are taught to be therapeutic with their children. The parent is taught specific techniques and is observed by the therapist interacting with the child in the play therapy room. Play therapy is a special process that focuses on a child's need to express their feelings through the use of play. Adults can be taught how to properly communicate with one another through psychoeducational approach of how communication works and being processed in a systemic setting.

"Decision-making counseling" which assists families in achieving enhanced, long-term self-reliance through gainful decision-making process activities. This counseling strategy utilizes an effective individualized case management model with an array of core and supportive activities across various situations that demand balanced decision making.

Life skills classes which can be offered on a wide range of topics such as anger management, stress reduction, balancing home and work, and meal planning on a budget. Other topics such as peer pressure, bullying, and planning for the future are typical areas of exploration. This may be offered in a single class format while others may meet once a week for several weeks.

In-depth counseling which can be designed to help family members, especially the growing adolescents explore pertinent issues and to develop the skills needed to self-direct and self-develop as fully functioning individuals.

\section{Conclusions}

Based on the premises of the data collected, the following statements are hereby concluded:

1) The Filipino families are still changing to stay relevant. These changes can be best understood through the constant changes in almost all facets of the society.

2) Changes may lead to challenges; thus, a guidance-oriented approach using a counseling program is a viable method in dealing with the resulting family issues along the way.

3) Unbalanced family relationship can lead to bigger societal problems. Hence, tackling family issues is in- 
directly harnessing the overall social and societal system.

4) Communication between and among family members is the single most effective tool to be harnessed in the Filipino families who might be experiencing family challenges.

5) Parenting seems to be the strongest precursor of the functioning (of dysfunction) of the overall family dynamics and cohesion among Filipinos.

\section{Recommendations}

Given the implications of the data gathered, the following are hereby recommended:

1) A more comprehensive program may be designed in order to serve better the changing needs of the Filipino Families (i.e., instead of a specific counseling program alone, a more encompassing guidance program may be designed).

2) Expand the socio-demographic characteristics of the families who participated in this study. More specifically, it is highly recommended, but not limited to, gather data from the highly urbanized areas, families belonging to middle up to higher socio-economic status, and those that significantly do not experience major familial challenges or problems.

3) Run a pilot study of the proposed and designed counseling program in the area where investigation was conducted. This is to turn the data into more meaningful development especially in rural areas.

4) A community-based "Family Guidance Center" is highly ideal especially in slum areas where both economic and educational grounds are lacking. This is ideally a component of an overall community mental health program which can be designed, piloted, and validated to as to serve as a baseline for a legislative proposal in the future.

\section{Acknowledgment}

The author would like to express his gratitude to the following individuals for their indispensable assistance and help in selecting and gatekeeping of this study's participants as well as for gathering most of its data: Joy Ann S. Miralles, Justine G. Liwag, Andrea Grace S. Dagmante, Raiza Dianne D. Dizon, Novia Rose F. Valmores, Christine C. Padilla, Jennifer A. Mendoza, Jova, S. Guba, Vince Gerald P. Soliven, Eduardo B. Dela Cruz, Ericka D. Ayap, Niña Kaye DT. Quezon, Patricia Marie E. Dela Cruz, Alma May C. Acosta, Zailah Yvette F. Tabilin, Criswayne A. Cadac, Immanuel E. Victorio, John Frank S. Mendoza, and Catherine Atejera.

\section{References}

Cruz, G. T. (2014). The Filipino family and youth in transition: Policy and program directions. Philippine Council for Population and Development Partner's Conference: Manila City.

Masanda, A. B. (2019). Understanding family dynamics of children under stress: A phenomenological inquiry. International Journal of Social Science and Humanities Research, 7(2), 1047-1056.

National Demographics and Health Survey, 2014. (2014).

Partners' Conference of the Philippine Center for Population and Development (PCPD), 2013. (2013).

Partners' Conference of the Philippine Center for Population and Development (PCPD), 2014. (2014).

Philippine Daily Inquirer. (2017). Philippines is world's number 1 in terms of time spent in social media. Retrieved from /http://technology.inquirer.net/58090/ph-worlds-no-1-terms-time- spent-social-media.

Villareal, M. G. B. (2018). The Filipino family today: A sociological perspective. Association of Catholic Universities in the Philippines Annual Convention: Manila City.

Young Adult Fertility and Sexuality Survey, 2014. (2014). 